\title{
The Role of Social Networks in Economic Decision Making Processes: The Case of Customers in Selected Banks of Shashemene Town, Oromia, Ethiopia
}

\author{
Bewunetu Zewude \\ Department of Sociology, Wolaita Sodo University
}

\begin{abstract}
The aim of this research was to assess the role of social networks (circles of friends, family members, close relatives, members of an ethnic group, congregates of a certain religion, etc) in peoples' economic decision making endeavors, focusing on how these variables influence customers' choice of banks in Shashemene town, Oromia, Ethiopia. Oromia International Bank and Cooperative Bank of Oromia were purposively selected as case studies with the intention that the nomenclature of the organizations is associated to the largest ethnic group in the study area (oromo). A descriptive survey research design was used in which quantitative data were collected from 237 samples selected based on convenience sampling technique. Data were then inserted in to SPSS version 20 for further analysis and presented using descriptive statistical tools. It was found that $79.3 \%$ of customers belong to the dominant ethnic group in the study area (Oromo). Respondents' decision of becoming customers of the current bank was made because there were employees in the bank with whom they had personal relationships, realizing that they can make transactions using their mother-tongue language, the nomenclature of the bank is associated to their ethnic identity, and due to recommendations from close relatives and friends that have been using the bank $(8 \%, 5.1 \%, 25.7 \%, 5.5 \%$, respectively). In addition, social networks also play the role of serving as sources of information for customers during the process of bank selection. Findings suggest that social networks influence individuals' economic behavior by supplying information, serving as role models, and recommending others to join an economic behavior similar to their own. Above all, people do not always behave after rational calculations of the costs and benefits of an economic action; instead, they also act according to the social setting in which they live, often in an attempt to comply with existing norms.
\end{abstract}

Keywords:- economic behavior, bank selection, social networks, rationality, ethnicity

DOI: $10.7176 / \mathrm{JCSD} / 52-02$

Publication date:October $31^{\text {st }} 2019$

\section{Background of the study}

Every day life involves varied level of economic action and decision making for individuals, organizations, and the society at large. The motives behind such economic behaviors vary both between and among these different units of analysis. Scientific explanations for the drives of economic decision making range from the very Smithian perspective to the modern elucidations emphasizing on the role played by social forces in determining individuals' economic decision making. Most researches undertaken so far on individuals' economic behavior have been largely influenced by the neo-classical tradition that emphasizes about how a person's economic decision making is determined by monetary incentives alone (Kinga, 2017:3).

At the first pole are rational choice theories defining individual decision making as the process of determining what options are available and then choosing the most preferred one according to some consistent criterion (Jonathan \& Paul, 2004). The "thin" version of the theory assumes that individuals are fully informed about all their decision alternatives, the probabilities of their outcomes and their consequences, in which there are no cognitive limitations in the perception or processing of this information. Above all, it is argued that individuals base their decision on cost-benefit calculations and choose the alternative that generates the highest expected utility (Brian, 2013).

There is, however, a long tradition of research suggesting empirical evidences refuting the arguments of rational choice theory and the most important of this being that real world choices often appear to be highly situated in the way in which a choice is posed, the social context of the decision, the emotional state of the decision maker, the addition of seemingly extraneous items to the choice set, and a host of other environmental variables (Jonathan $\&$ Paul, 2004). Individuals often make choices that are sub-optimal from the economic perspective and their rationality is bounded due to limitations in their cognitive capacities (Thaler, 1980). People frequently act on emotions, by a force of habit, care about others' welfare and fairness, are influenced by the context of the decision, use heuristics, and make biased judgments (Kinga, 2017; Michael \& Satoshi, 1997).

Social network theories produced an alternative view to rational choice theories where the attributes of individuals are less important than their relationships and ties with other actors within the network (Alex, 2011). Social network theories contend that many economic interactions are embedded in networks of relationships and the structure of the network plays an important role in governing the outcome (Matthew, 2009). According to 
Granovetter (1985), individuals are embedded in networks of social relations and it is these relations that influence how people behave in the economy. Social relations, rather than institutional arrangements or generalized morality, are mainly responsible for the production of trust in economic life (PP. 491).

A social network is a social structure made up of individuals or organizations which are connected by one or more specific types of interdependency, such as friendship, kinship, ethnicity, common interest, financial exchange, dislike, sexual relationships, or relationships of beliefs, knowledge or prestige (Alex, 2011). Among others, ethnicity has now taken a predominant position in terms of serving people as the largest social network structure in Ethiopia. Ethnic sentiments have their own attachments with employment, business arena, and public investment which directly or indirectly affect the economic performance of individuals and institutions. This bank belongs to... ethnic group; my boss is from ....ethnic group; I can't get my business license because I am...; He has this large construction company because he is....; I don't bother about this public investment because the beneficiaries are from.... ethnic group, etc are some of the conversations in our every day interaction which enclose ethnicity and interrelated issues (Asnake, 2014:5).

Zahorik (2005) argued that ethnicity in Ethiopia is being a major obstruction for socio-economic and political development because of its politicization nature where by majority of decision-making processes are done through ethnic lenses. According to Alesina and La Ferrara (2003), ethnicity can affect economic choices through directly involving with individual choices where by individuals may strive for positive utility of their own ethnic group members and negative utility to others. Ethiopian business enterprises seem to understand the fact that ethnicity can greatly influence peoples' economic actions often by intervening in self-interest driven utility maximizations and rational calculations. Since recent years, most business organizations have experienced significant shifts in nomenclature, the goal of which remains attracting ethnic enclaves through creating associations of identity. Such emerging pattern in ethnic identity-based nomenclature is more pronounced among the banking, insurance, and micro-finance institutions. Social factors, particularly social networks as stipulated by ethnicity, can influence economic behavior in manifold ways and the true underlying mechanism of social influences is still relatively unexplored (Kinga, 2017:3). The purpose of the present research was therefore; to assess the impact of social networks on bank customers' decision making processes in Shashemene town, Ethiopia.

\section{Methods and Materials \\ Methods and data sources}

Primary data were collected using survey method. Survey method was used mainly to gather quantifiable data regarding the frequency of cases occurring and their patterns of distribution among the various segments of the study population. For this purpose, quantitative data were collected through a well prepared intervieweradministered questionnaire that was later translated in to locally understandable language, especially to make it suitable for enumerators. The questionnaire contained questions related to what customers take in to account when choosing a given bank. Data collectors were trained about the objectives and overall purpose of the research and made to be familiar with the data collection instruments and then guided about how to best approach respondents so as to collect quality data. The accuracy and relevance of the questionnaire was pretested using a pilot study on same study population but a different sample few days before starting the actual data collection activity. In addition, strict procedures of data quality management tasks were undertaken, especially through serious supervision and follow-up. Data collection activities were undertaken in June, 2019. Furthermore, existing literatures were intensively reviewed to supplement first-hand data sources. Accordingly, books, articles, both published and unpublished research findings, conference proceedings, and publications of international organizations were assessed and reviewed.

\section{Sample size and procedure}

With a very fluctuating number of customers, often switching from one to another, it was almost impossible to be able to obtain the exact number of customers in the banks where this study was undertaken. This implies that the sampling frame of the study's population from which accurate samples can be drawn using probability sampling technique was hardly found among the target banks. Consequently, convenience sampling method of the nonprobability sampling cluster was used. First, Shashemene town was purposively selected due to accessibility of the town to the researcher which creates an easier way in to data gathering and frequent field visits. Moreover, the town is selected for the fact that it is one of the main strategic trade centers of Ethiopia, having all the gateways to the major regional cities and the capital of the country. Due to such geographic and demographic significances and the resulting lucrative business activities it hosts, the town has always been serving as one of the most preferred area to open branches and sub-branches of banks by investors. The abundance availability of various bank brands therefore, served as one of the reasons to choose Shashemene as the research site for the current study. The survey conveniently targeted customers of private banks the names of which are preceded by terms reflecting belongingness to a particular ethnic group, particularly Oromia International Bank and Cooperative Bank of Oromia. Customers of these banks were selected with the hypothesis that they might have preferred the banks for 
the mere reason that the nomenclature of the banks is associated to the ethnic enclave (Oromo) to which the customers are affiliated. Accordingly, 250 persons selected on the basis of convenience sampling technique were considered for the survey from which 237 cases were contacted making the response rate $94.8 \%$.

\section{Method of Data analysis}

After the data were collected, data cleaning and organization tasks were undertaken in order to check for completeness. It was then coded and entered in to SPSS version 20 for further processing. Descriptive statistical tools, including, frequency tables, charts, and percentages were utilized to present frequencies and differential distribution of cases across the various sub-groups within the survey participants.

\section{Ethical Considerations}

The researcher has obtained ethical clearance from the concerned ethical approval committee of Wolaita Sodo University. An informed consent was gained by informing the research participants about the objectives and rationale of undertaking the research. Furthermore, up on collecting data, respondents were given an orientation not to write their names on the questionnaire in order to keep their personal identity anonymous. The researcher further ensured this by not indicating the exact names of any of the respondents. Above all, each respondent was informed about the level of freedom that is provided in case one wants to withdraw from the research.

\section{Results and discussion \\ Socio-demographic characteristics of respondents}

Table 1: frequency distribution of respondents based on their socio-demographic characteristics

\begin{tabular}{|c|c|c|}
\hline Variables & Categories & Frequency (\%) \\
\hline \multirow[b]{2}{*}{ Sex } & Male & $173(73.0 \%)$ \\
\hline & Female & $64(27.0 \%)$ \\
\hline \multirow{6}{*}{ Age } & $1-20$ & $23(9.7 \%)$ \\
\hline & $21-30$ & $112(47.3 \%)$ \\
\hline & $31-40$ & $69(29.1 \%)$ \\
\hline & $41-50$ & $18(7.6 \%)$ \\
\hline & $51-60$ & $13(5.5)$ \\
\hline & $\geq 61$ & $2(0.8 \%)$ \\
\hline \multirow{5}{*}{ Ethnicity } & Oromo & $188(79.3 \%)$ \\
\hline & Amhara & $19(8.0 \%)$ \\
\hline & SNNPs & $17(7.2 \%)$ \\
\hline & Tigray & $2(0.8 \%)$ \\
\hline & Other & $11(4.6 \%)$ \\
\hline \multirow{2}{*}{$\begin{array}{l}\text { Residential background } \\
\text { (raised-up area) }\end{array}$} & Rural & $103(43.5 \%)$ \\
\hline & Urban & $134(56.5 \%)$ \\
\hline \multirow{6}{*}{ Religion } & Orthodox Christian & $56(23.6 \%)$ \\
\hline & Muslim & $115(48.5 \%)$ \\
\hline & Protestant & $53(22.4 \%)$ \\
\hline & Catholic & $7(3.0 \%)$ \\
\hline & Non-believers & $1(0.4 \%)$ \\
\hline & Others & $5(2.1 \%)$ \\
\hline \multirow{9}{*}{ Education } & Never attended school & $2(0.8 \%)$ \\
\hline & $1-4$ & $6(2.5 \%)$ \\
\hline & $5-8$ & $33(13.9 \%)$ \\
\hline & $9-10$ & $57(24.1 \%)$ \\
\hline & $11-12$ & $27(11.4 \%)$ \\
\hline & $10+3$ & $41(17.3 \%)$ \\
\hline & BA/Sc degree & $57(24.1 \%)$ \\
\hline & MA/Sc degree \& above & $14(5.9 \%)$ \\
\hline & Total & $237(100.0 \%)$ \\
\hline
\end{tabular}

Source: survey data, 2019

As shown in table 1 , most of the respondents are male $(73 \%)$ whereas the remaining $(27 \%)$ are females. Moreover, 112 of 237 respondents are between 21-30 years old while people 61 and above years of age constitute relatively the smallest percentage $(0.8 \%)$ in the distribution. In terms of ethnicity, respondents that belong to the oromo ethnic group take the lion's share $(79.3 \%)$ and those who claim to belong to the tigray ethnic group consist 
$0.8 \%$ of the respondents. $56.5 \%$ of survey respondents replied that their residential (raised-up) area is urban and $43.5 \%$ answered to have a rural residential background. Furthermore, Muslims constitute the largest (48.5\%) share of respondents followed by orthodox Christians (23.6\%). Above all, respondents educated both grade 9-10 and possessing BA/Sc degree make up the largest frequency in the distribution whereas those that have never attended school got the least share $(0.8 \%)$.

The role of social networks on customers' bank choices

Table 2: factors that motivated customers when choosing the bank at which they are customers

\begin{tabular}{lr} 
Nomenclature of the bank related to customers & Frequency (\%) \\
ethnicity & $61(25.7 \%)$ \\
knowing employees & $19(8.0 \%)$ \\
Advertisement & $14(5.9 \%)$ \\
language mostly spoken in the bank & $12(5.1 \%)$ \\
informed about its better service & $65(27.4 \%)$ \\
number of branches & $6(2.5 \%)$ \\
relatives/friends previously customers & $13(5.5 \%)$ \\
physical proximity & $14(5.9 \%)$ \\
receive salary through the bank & $11(4.6 \%)$ \\
accidental/unplanned & $21(8.9 \%)$ \\
other & $1(0.4 \%)$ \\
Total (N) & $\mathbf{2 3 7}(\mathbf{1 0 0 . 0 \% )}$ \\
\hline
\end{tabular}

Table 2 reveals the role of social networks in terms of influencing individuals' behavior of making economic choices. In addition to the $27.4 \%$ of respondents who have chosen their current financial service provider on the basis of information about its better services, respondents' decision of becoming customers of the current bank was made because there were employees in the bank with whom they had personal relationships, realizing that they can make transactions using their mother-tongue language, the nomenclature of the bank is associated to their ethnic identity, and hearing that their close relatives and friends have been using the bank $(8 \%, 5.1 \%, 25.7 \%$, $5.5 \%$, respectively).

Survey participants were asked to disclose whether or not the decision to choose the current bank was based on collection of sufficient information. Accordingly, $63 \%$ of them replied that they have gathered enough information while the remaining 37\% answered that their decision of becoming customers of the present banks was not based on sufficient information. Chart 1 shows the percentage distribution of the various sources of information for respondents who said to have made their decision on enough information. As indicated in the chart, media was the major source of information for respondents $(22 \%)$, followed by friends $(21.5 \%)$, colleagues $(9 \%)$, close relatives $(7 \%)$, and family members $(2.1 \%)$.

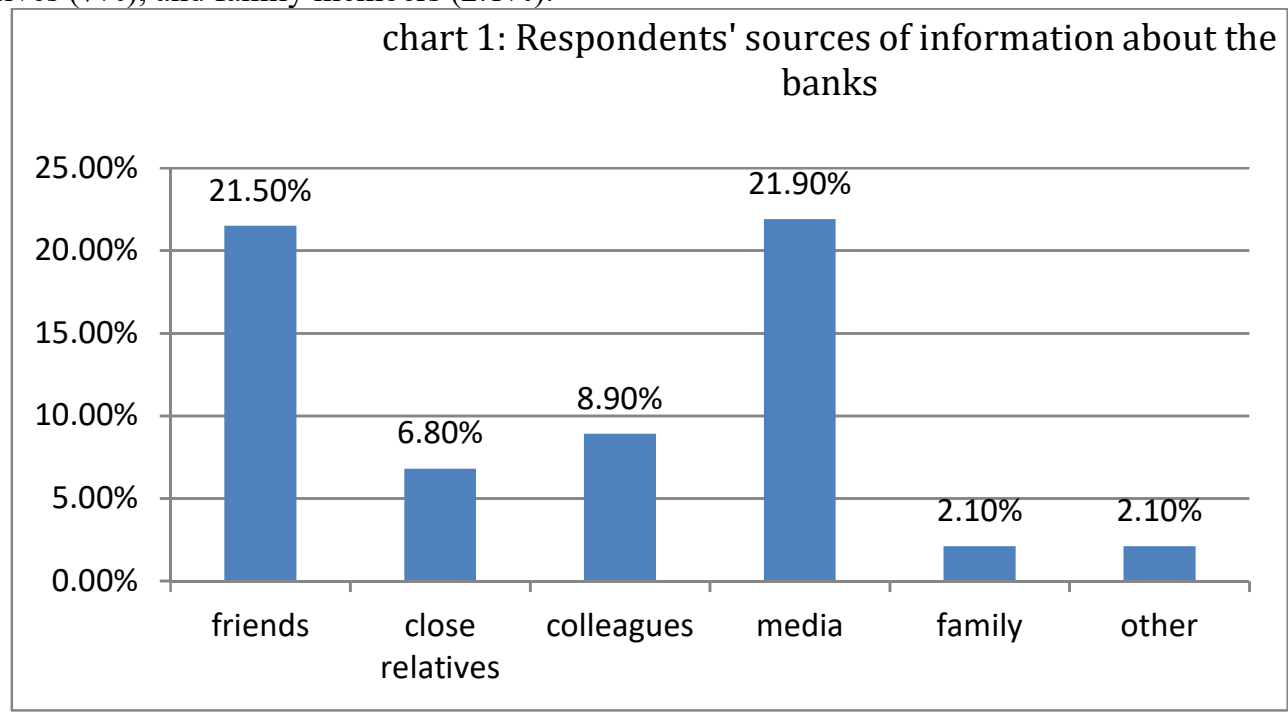

The role of social networks on customers' choice of banks can also be observed in terms of the criteria that they take in to consideration when selecting a given bank, as shown in table 3 below. The name of the bank and its association to their ethnic identity ( $52.3 \%$ very necessary, $27 \%$ necessary), the nature of social relations maintained between employees of the bank and potential customers ( $24.1 \%$ very necessary, $30 \%$ necessary), the presence of close relatives and friends that have been using the bank before them $(27.4 \%$ very necessary, $30.8 \%$ 
necessary), whether or not their mother-tongue language is being spoken in the bank (54\% very necessary, $24.1 \%$ necessary) are some of the factors that influence customers' choice of banks.

Table 3: percentage distribution of the criteria customers consider when choosing a bank

\begin{tabular}{|l|c|c|c|c|c|}
\cline { 2 - 5 } \multicolumn{1}{c|}{} & \begin{tabular}{c} 
Very \\
\multicolumn{1}{c|}{ necessary }
\end{tabular} & Necessary & Neutral & Unnecessary & $\begin{array}{c}\text { Very } \\
\text { Unnecessary }\end{array}$ \\
\hline Name of the bank & $52.30 \%$ & $27.00 \%$ & $8.90 \%$ & $4.60 \%$ & $7.20 \%$ \\
\hline Proximity & $59.5 \%$ & $34.2 \%$ & $3 \%$ & $2.5 \%$ & $0.8 \%$ \\
\hline Physical appearance & $29.5 \%$ & $49.8 \%$ & $10.5 \%$ & $5.9 \%$ & $4.2 \%$ \\
\hline Extra working hours & $43.5 \%$ & $37.1 \%$ & $12.2 \%$ & $4.6 \%$ & $2.5 \%$ \\
\hline No. of branches & $63.7 \%$ & $30.8 \%$ & $3.4 \%$ & $1.7 \%$ & $0.4 \%$ \\
\hline Relation with employees & $24.1 \%$ & $30 \%$ & $21.5 \%$ & $15.2 \%$ & $9.3 \%$ \\
\hline Mobile/internet banking & $60 \%$ & $25.7 \%$ & $11 \%$ & $2 \%$ & $1.3 \%$ \\
\hline Relatives/friends using the bank & $27.4 \%$ & $30.8 \%$ & $24.1 \%$ & $9.7 \%$ & $8 \%$ \\
\hline Parking space & $41.4 \%$ & $32.5 \%$ & $22.4 \%$ & $1.7 \%$ & $2.1 \%$ \\
\hline Reception & $78.5 \%$ & $19.4 \%$ & $0.8 \%$ & 0 & $1.3 \%$ \\
\hline Complaints handling & $62.4 \%$ & $28.7 \%$ & $5.9 \%$ & $2.1 \%$ & $0.8 \%$ \\
\hline Low service cost & $40.1 \%$ & $25.3 \%$ & $12.2 \%$ & $5.1 \%$ & $17.3 \%$ \\
\hline High saving interest rate & $35 \%$ & $25.3 \%$ & $15.2 \%$ & $0.4 \%$ & $24.1 \%$ \\
\hline Easy way of getting credit & $65 \%$ & $15.2 \%$ & $14.8 \%$ & $1.3 \%$ & $3.8 \%$ \\
\hline Prizes & $73 \%$ & $20.7 \%$ & $4.2 \%$ & $0.8 \%$ & $1.3 \%$ \\
\hline Low interest rate on loan & $14.8 \%$ & $23.2 \%$ & $21.1 \%$ & $3 \%$ & $38 \%$ \\
\hline Language & $54.00 \%$ & $24.10 \%$ & $16.50 \%$ & $1.30 \%$ & $4.20 \%$ \\
\hline customer service & $93.30 \%$ & $5.50 \%$ & $1.30 \%$ & 0 & 0 \\
\hline Abundance of ATM machines & $68.8 \%$ & $16.5 \%$ & $11.4 \%$ & $2.1 \%$ & $1.3 \%$ \\
\hline Saving interest rate & $35.00 \%$ & $25.30 \%$ & $15.20 \%$ & $0.40 \%$ & $24.10 \%$ \\
\hline location & $67.50 \%$ & $29.50 \%$ & $1.30 \%$ & $1.30 \%$ & $0.40 \%$ \\
\hline
\end{tabular}

Source: - survey, 2019

The presence of an attractive customer services has appeared to be the most valued criteria $(93.3 \%$ very necessary, $5.5 \%$ necessary), followed by reception (78.5\% very necessary, $19.4 \%$ necessary), the presence of prizes (73\% very necessary, $20.7 \%$ necessary), availability of ATM machines in different locations $(68.8 \%$ very necessary, $16.5 \%$ necessary), the relative location of the bank to home and work place $(67.5 \%$ very necessary, $29.5 \%$ necessary), an easy way of getting bank credit (65\% very necessary, $15.2 \%$ necessary), and the manner in which complaints are handled (62.4\% very necessary, $28.7 \%$ necessary) as shown in table 3 . It can be understood from the table that customers' criteria of choosing a given bank involve a mix of both rationality driven motivations and the influence of social networks.

\section{Discussion}

Findings of the present survey revealed that about $80 \%$ of respondents (customers) belong to an ethnic group that is directly associated to the nomenclature of the banks. This is accompanied by $25.7 \%$ of respondents who replied that they have chosen the banks mainly because of the fact that the nomenclature of the banks has something to do with the ethnic group to which they are ascribed. This finding suggests that ethnicity as a social network intervenes with customers' decision of choosing a given bank. Moreover, $8 \%$ of respondents replied that they have chosen the bank because there are employees in the bank with whom they have personal relationships. The presence of people speaking similar mother-tongue language to customers has also been one of the factors that influence customers' choice of banks in the study area (5.1\%). Above all, peoples' choice of banks has also been made based on recommendations made from friends and close relatives who have been using the bank before $(5.5 \%)$.

The findings of the present research are consistent with the findings of Jamealla (2016). After studying the influence of ethnicity on consumer behavior, the researcher found that a higher number of research participants used service providers from their ethnic background. It was also found that ethnicity affects the level of trust that customers make on various suppliers of goods and services. Moreover, Forney and Rabolt (1985-86) also argued that individuals with a strong sense of their ethnic identity are more inclined to favor ethnic food or ethnic dress than individuals with a weak sense of their ethnic identity. Production, exchange and consumption of goods and services largely take place in social settings where the patterns and nature of interactions influence, and are influenced by, economic activity (Granovetter, 973).

According to the data in the present study, social networks also play the role of serving as sources of information for customers during the process of bank selection. As presented above, in addition to media which appeared to be the major information outlet in this study $(21.9 \%)$, friends, close relatives, colleagues, and family 
members $(21.5 \%, 6.8 \%, 8.9 \%, 2.1 \%$, respectively) were sources of information for respondents. In addition, social networks have also been among the criteria that customers take in to consideration when choosing banks. The nomenclature of the bank and its association to the ethnic identity of customers $(52.3 \%)$, the presence of people and employees in the bank speaking languages similar to customers' mother-tongue language (54.3\%), the presence of friends and close relatives who have been using the bank previously (27.4\%), having personal relationships with employees of the bank $(24.1 \%)$ are some of the criteria that customers consider very necessary to become customers of a given bank.

The findings of the present research are consistent with findings of other authors. Forinstance, the finding that people also rely on others' recommendation for making decisions is consistent with the finding of Syed \& Guruswamy (2007). They suggested that the majority of customers in Mekelle city seeking services from a retail bank make the choice based on other customers' recommendations. In addition, the finding that the presence of personal relationships with employees of the bank was among the criteria for bank selection is consistent with Almossawi (2001). He found that reputation of a bank, friendliness of personnel working in a bank, availability and location of ATM machines, and the presence of adequate parking space as the factors affecting bank selection criteria employed by college students in Bahrain. Above all, the present research contributes empirical findings that were not addressed by previous studies on related topics. Although the influence of some aspects of social networks on peoples' economic decision making processes were discussed by other researchers before, the impacts of ethnicity, language, and close relatives have not been addressed by previous studies.

\section{Conclusion}

The purpose of the research was to find out the impacts of various social networks on individuals' economic decision making behavior with particular emphasis on customers of selected banks in Shashemene town, Ethiopia. Having noted the proliferation of business organizations adopting nomenclatures driven from the name of the relatively dominant ethnic group residing in the study area, the researcher purposively selected Oromia International bank and Cooperative Bank of Oromia. Using survey research method, a structured questionnaire was prepared to collect data from 250 conveniently selected respondents, from which 237 completed cases were gathered. Data inserted in to SPSS version 20 were analyzed and presented using descriptive statistical techniques.

Findings revealed that social networks play a paramount role both in motivating as well as shaping individuals' economic decision making enterprises. Social networks, such as members of an ethnic group, family members, close relatives, friends and colleagues all influence individuals' economic behavior by supplying information about a given business organization, serving as role models, and recommending others to join an economic behavior similar to their own. Furthermore, results of the present study suggest that people do not always behave after rational calculations of the costs and benefits of an economic action; instead, there are also circumstances in which people act according to the social setting in which they live. In other words, people often act just in response to the demands of the social environment to which they are subscribed and the sense of belongingness to a particular social group also influences their economic decision making behavior.

\section{References}

Alesina, A. \& Perotti, R.(1996). Income distribution, political instability, and investment. European Economic Review, Vol.40, pp.1203-1228.

Alex Kosorukoff. (2011). Social network analysis: theory and applications, Passmore, D.L

Almossawi, M. (2001). "Bank Selection Criteria Employed by College Students in Bahrain": An Empirical Analysis. International Journal of Bank Marketing, 19(3), 115-25.

Asnake Anteneh. (2014). Ethnicity and its impact on economic development in Africa: case studies from Ethiopia and Nigeria. Unpublished thesis submitted to Addis Ababa University, school of graduate studies, in partial fulfillment for the requirements of obtaining Masters Degree in African Studies.

Brian A. Hoey. (2013). Rational Choice Theory. Sage Publications, Inc

Forney, J. \& Rabolt, N. (1985-1986). Ethnic identity: its relationship to ethnic and contemporary dress' cited in Chattaraman, V \& Lennon, SJ 2008, 'Ethnic identity, consumption of cultural apparel, and self perceptions of ethnic consumers. Journal of Fashion Marketing and Management, vol. 12, pp. 518-531.

Granovetter, M.S. (1973), The strength of weak ties, American Journal of Sociology 78, 13601380.

Granovetter, M. (1985). Economic Action and Social structure: the problem of Embeddedness, American Journal of Sociology, Volume 91, Issue No.3, PP. 481-510

Jamealla V Intharacks. (2016). The Influence of Ethnicity on Consumer Behavior: A study of inter-generational and inter-group differences. Unpublished dissertation paper submitted to Western Sydney University in partial fulfillment for the degree of doctor of philosophy.

Jonathan Levin. \& Paul Milgrom. (2004). Introduction to Choice Theory

Kinga Posadzy. (2017). Social and Economic factors in decision making under uncertainty: five essays in behavioral economics. Linkoping University, faculty of arts and science 
Matthew O. Jackson. (2009). Networks and Economic Behavior. Annual review of economics, Vol. 1, pp. 489513

Michael Hechter, Satoshi Kanazawa. (1997). Sociological rational choice theory. Annu. Rev. Socio. 23:191-214

Syed, A. M., \& Guruswamy, D. (2007). Customer preferences for retail banking services in Ethiopia: with special reference to retail banks in Mekelle City.

Thaler, Richard. (1980). 'Toward a positive theory of consumer choice, Journal of Economic Behavior \& Organization, 1: 39-60.

Zahorik, J. (2011). Ethnicity and Nationalism in Ethiopia: Some Recent Reflections. The Annual of Language \& Politics and Politics of Identity, Vol. V. pp. 91- 108. 